\title{
ROPER, Lyndal, Oedipus and the Devil. Witchcraft, sexuality and religion in early modern Europe
}

\section{Olivier Christin}

\section{OpenEdition}

\section{Journals}

Édition électronique

URL : https://journals.openedition.org/ifha/1535

DOI : 10.4000/ifha.1535

ISSN : 2198-8943

\section{Éditeur}

IFRA - Institut franco-allemand (sciences historiques et sociales)

\section{Référence électronique}

Olivier Christin, «ROPER, Lyndal, Oedipus and the Devil. Witchcraft, sexuality and religion in early modern Europe », Revue de l'IFHA [En ligne], Date de recension, mis en ligne le 01 janvier 1997, consulté le 21 septembre 2021. URL : http://journals.openedition.org/ifha/1535; DOI : https://doi.org/10.4000/ifha. 1535

Ce document a été généré automatiquement le 21 septembre 2021.

(C)IFHA 


\title{
ROPER, Lyndal, Oedipus and the Devil. Witchcraft, sexuality and religion in early modern Europe
}

\author{
Olivier Christin
}

1 Il s'agit ici avant tout d'un recueil d'articles publiés en allemand ou en anglais entre 1989 et 1993, précédés d'une assez longue préface, théorique et militante, qui dessine les contours de ce que pourrait être une nouvelle Gender History attentive aux enjeux proprement physiques, corporels et sexuels des relations entre hommes et femmes. Lyndal Roper ne recule pas devant la polémique et prend, parfois sèchement, ses distances à l'égard des études inspirées par Elias, Weber l'anthropologie historique ou le concept de Sozialdisziplinierung (Social Discipline).

2 L'ensemble ne manque ni de force, ni d'intérêt, même le choix des objets jugés pertinents pour poser des conclusions générales très ambitieuses étonne parfois par son caractère extrême: la prostituée, le prêtre catholique (vu par les prédicateurs protestants), le viol sont-ils vraiment les figures emblématiques des relations entre sexes? L'érudition de l'auteur et la subtilité de certaines analyses déjouent de toute façon les critiques trop rapides. A ce titre, il faut absolument lire l'excellente critique de la thèse de la Sozialdisziplinierung que propose L.R.: "Drinking, whoring and gorging: british indiscipline and the formation of Protestant identity « (p.145-167). L'auteur souligne tout d'abord que la Sozialdisziplinierung n'est pas une conséquence naturelle des progrès de l'État central, mais l'enjeu et le résultat de conflits précis à l'intérieur même des villes et des territoires. En outre, loin de façonner un sujet unique, soumis uniformément à l'État, elle accentue les distinctions sociales et sexuelles, par exemple à propos de l'adultère: les relations adultères entre maître et servante sont passibles de sanctions trois fois plus lourdes que les autres adultères. Enfin, L.R. propose de voir également dans les "pulsions« que les autorités religieuses et politiques tenteraient de brider des créations culturelles modernes et non de simples affects antihistoriques: un survol rapide de la "littérature de l'excès« (Fischart, Hans Sachs, Dedekind) du XVIe s. apporte sur ce point des éléments de réflexion stimulants. 
3 Olivier CHRISTIN 